\title{
A cost-effective method for monitoring airborne particulate matter using tabletop SEM-EDS
}

\author{
K. Wilkinson, J. Lundkvist, G. Seisenbaeva \& V. Kessler \\ Department of Chemistry, Inorganic Chemistry, \\ Swedish University of Agricultural Sciences, Uppsala, Sweden
}

\begin{abstract}
Inhalable airborne Particulate Matter (PM) has been linked to adverse effects in the airways and cardiovascular system in humans leading indirectly to hospitalization and possibly premature death. The need to monitor these on a local level has recently been realized with the emergence of low cost tabletop Scanning Electron Microscopes (SEM) with high magnification possibilities offering a quick and easy way of analyzing PM down to 300 nanometres in size. The ease of use of these instruments makes them suitable for an untrained person to routinely monitor elemental constituents of individual particles and possibly linking them to inherent health risks. In this study particles from outdoor air were collected onto Polyamide filters and analyzed using tabletop SEM utilizing Energy Dispersive Spectroscopy (EDS) to determine and identify their chemical composition. 341 particles were successfully characterized and classified in relation to their chemical identity and origin. The regional differences in the samples could be related to the location of sample collection proving that tabletop SEMs offers a possibility of air quality monitoring in relation to the particle impurities.
\end{abstract}

Keywords: monitoring, particulate matter, PM, airborne, tabletop, SEM, EDS, EDAX, elemental analysis.

\section{Introduction}

People spending time in- or outdoors are all subject to inhalable Particulate Matter (PM) in different forms such as an ever present ambient mineral 
suspension, vehicular and/or industrial activity or dust. Concentrations of PM vary on a local scale but many studies have linked inhaled PM to negative health effects $[1,2]$. In general PM of size $10 \mu \mathrm{m}$ and smaller, i.e. PM10, are viewed as inhalable. The three main inhalable particle size classes of Coarse Mode (PM10), Fine Mode (PM2.5) and Ultrafine Mode (PM0.1) are believed to have in many cases different sources and subsequently differing health impact [3]. Inhaled PM is deposited mainly in the lungs when inhaled and, depending on size mode, enter different regions of the lungs where the inherent toxicity of the PM comes into effect. Reports by Donaldson et al. [4], Sioutas et al. [5], and Delfino et al. [6] indicate that PM0.1 are retained in the lungs but are of a small enough size to enter the blood stream directly through the gas exchange mechanism in the lungs and Nemmar [7] reports that particle solubility issues may play a significant role in the health impact of this size mode of particles.

The European Union and the United States have both implemented legislation for permitted levels of PM in inhabited areas adopted from recommendations from the World Health Organization (WHO) [8]. Due to early reports collated by Pope [9] on their detrimental health effects only PM10 and PM2.5 are limited thus and are subdivided into an allowed annual mean of exposure, which can be exceeded only once per year and an allowed 24-hour exposure, allowance subject to multiple surpasses annually. Brunekreef and Holgate [10] offer a good overview of the specific national limitations of PM emissions. outdoor PM emissions are derived mainly from traffic-related and combustible sources (Bernstein et al. [11]), and are mixed together with ambient suspended mineral materials whereas indoor sources vary greatly.

PM-levels are often reported in terms of grams per cubic-meter $\left(\mu \mathrm{g} / \mathrm{m}^{3}\right)$ determined either gravimetrically or computed from a mean particle abundance measurement using a mean density of background materials. They are also often categorized into the two aforementioned fractions: PM10 and PM 2.5. This information is of a very general character and does not really differentiate PM on a chemical level, where inherent toxicities can vary greatly for comparable amounts of different materials. As such the health impact should be considered different for different inhaled materials [12-14]. Due to revisions to several countries PM emission policies and rising environmental awareness the need to monitor and characterize PM is growing. This characterization should not be limited only to size, shape and a general assumption of constituents but should also provide data on chemical species and inherent toxicity derived from toxicological studies (De Viscaya-Ruiz et al. [13]).

Characterization of PM on a routine basis is possible. The most common methods are off-line where samples are collected in the field and then analyzed in the laboratory utilizing microanalysis techniques such as Scanning electron microscopy (SEM) and X-ray fluorescence (XRF) [15-21]. Chemical information can thus be acquired from individual particles using Energy Dispersive Spectroscopy (EDS) and a certain degree of automation is possible for larger sampling sizes. The main disadvantages of this type of analysis is that it is limited by particle size, where routine measurements of particles that are significantly smaller than $1 \mu \mathrm{m}$ can be fraught with difficulty and result in poor 
analysis results. Running costs of instruments and expert personnel for these applications could be added drawbacks hindering routine use. For smaller size modes of particles $(\mathrm{PM}<1)$ other more sensitive methods such as Inductively Coupled Plasma Mass Spectroscopy (ICP-MS) and Gas-Chromatography Mass Spectroscopy (GC-MS) used by Kleeman et al. [22]. These instrumentation methods are also well suited for analysis of the organic elements, which SEM and XRF can analyze to some extent, and also some functional groups or molecules can also be distinguished providing some clues as to possible toxicological effects from analyzed particles. Often they are less well suited for analysis of larger particles as some material break-up or desorption from the particle is needed for analysis and this invariably takes place on the surface of the particle and thus a proper representation of the particle as a whole remains uncertain, although it could be argued that any toxicological effects from particles arises from surface transactions making the surface the valid part to analyze it is also important not to disregard solubility of chemical species from particles. On-line analysis of aerosols is possible using Aerosol Time-of-Flight Mass Spectrometry (ATOF-MS) in that an aerosol is introduced into the instrument and real-time analysis of the aerosol is made in a similar manner as in ICP- and GC-MS [23]. ATOF-MS is a powerful tool for analysis due to fast 'fingerprinting' of known chemical species and classification of typical particle emission types that can be cross-referenced in a database of known species [24]. Again it is well suited for analysis of sub-micrometer particles, if not the premier method for this application and outperforms SEM and XRF in this regard.

Recent developments in commercially available tabletop Electron Microscope equipment have led to new SEM development to bridge the gap between optical microscopes and conventional SEMs. Tabletop SEMs are both cheaper and easier to use than more conventional instruments and maintain magnification possibilities up to $\mathrm{x} 20,000$ and resolution possibilities that are close in order to more conventional apparatus. These kinds of instruments have fixed running settings, such as accelerating voltage, emission current or degree of vacuum when imaging a sample. Conversely this apparent disadvantage can be made an advantage as the factory settings of this kind of instrument are well suited for viewing a multitude of samples with very little to no pretreatment of samples, making it easy to use for an untrained professional. These types of tabletop Electron Microscopes are thus mainly suited for routine work. Tabletop SEMs can be fitted with EDS-detectors giving the user the option of scanning an area or a spot for elemental composition. This has been utilized in the current study. Particles caught on a substrate can in this way be analyzed for atomic content by focusing the electron beam in the instrument on an isolated particle and detecting X-ray emissions in the process. Spot sizes vary but generally they are approximately $1 \mu \mathrm{m}^{2}$ for this type of instrument. New piezoelectrically-cooled Silicon Drift Detectors (SDD) can be brought down in temperature to approximately $-40^{\circ} \mathrm{C}$ and alleviate the use of liquid nitrogen as cooling agent substantially reducing running costs.

In this study a possible methodology of particle microanalysis using a tabletop SEM was tested, specifically a Hitachi TM-1000 SEM with EDS. These 
come fitted with a backscatter electron detector that not only gives visual imaging magnification up to $\mathrm{x} 10,000$ but the backscatter also distinguishes electron density in the sample showing denser, i.e. heavier elements as brighter and the lighter elements as darker. The instrument runs under variable pressure mode (VP) which means in essence that excess charge build-up on the sample surface is led away by the trace amounts of gas in the sample chamber thus negating the requirement of coating of most samples [25]. The EDS is capable of qualitatively detecting elements of atomic number 11 (sodium, $\mathrm{Na}$ ) and higher in individual samples down to $300 \mathrm{~nm}$ in size, in some cases even smaller samples can be analyzed. Detection of elements lighter than $\mathrm{Na}$ are currently not possible using the standard instrumentation and thus the characterization of elements in the organic mode are beyond the scope of this analysis method. Comparative quantification of elements in particles is possible with computer software calculations on collected spectra presenting a possibility of tracing the particle to a predetermined source, cross-referencing reference- and standard materials. The instrument used in this study has an energy resolution of $165 \mathrm{eV} / 148 \mathrm{ev}$ (copper$\mathrm{K} \alpha$ resp. equivalently manganese- $\mathrm{K} \alpha$ ) and elemental quantification is provided by a calculated value presented as fractions of weight percent per identified element. The sensitivity of analysis is dependant on sample porosity, identifiable elemental density and detector gain among others but is accurate to within 0.1$0.5 \mathrm{wt} \%$. This limit was tested by the authors on a substrate material infused with different salts and will be published elsewhere. In this way specific areas of emissions may be characterized by characterization of the elemental inorganic constituents of emitted particles making routine monitoring a possibility. It is underperforming compared to the more technologically advanced analysis variants described above but holds it's own when comparing full instrumentation cost, which is in the region of $\$ 100,000 \mathrm{US}$, and it's ease of use.

For the testing of the monitoring method particles were collected onto porous polyamide filters by means of suction from outdoor air in and around the city of Uppsala, Sweden. The county of Uppsala has approximately 190,000 inhabitants and the city of Uppsala represents a large size Swedish city. Major anthropogenic PM sources in the county area are traffic-, rural-, and biomassburning activities from private households and incineration plants. The annual mean PM10 concentration for Uppsala City, according to the organization LVF [26], was below $30 \mu \mathrm{g} / \mathrm{m}^{3}$ in 2007 , although daily variances occurred that were much higher $\left(120 \mu \mathrm{g} / \mathrm{m}^{3}\right.$ in the most extreme case $)$.

\section{Materials and methods}

\subsection{Locations for particulate air sampling}

Air sampling was performed on the 14th and 19th of May 2008 on seven different locations. The sampling locations were arbitrarily selected following two criteria: I) availability of electrical current for air suction units, II) variation of urban, rural and industrial settings. The sites were chosen to represent a large size city with locales of industrial and vehicular activity and rural sites serving as 


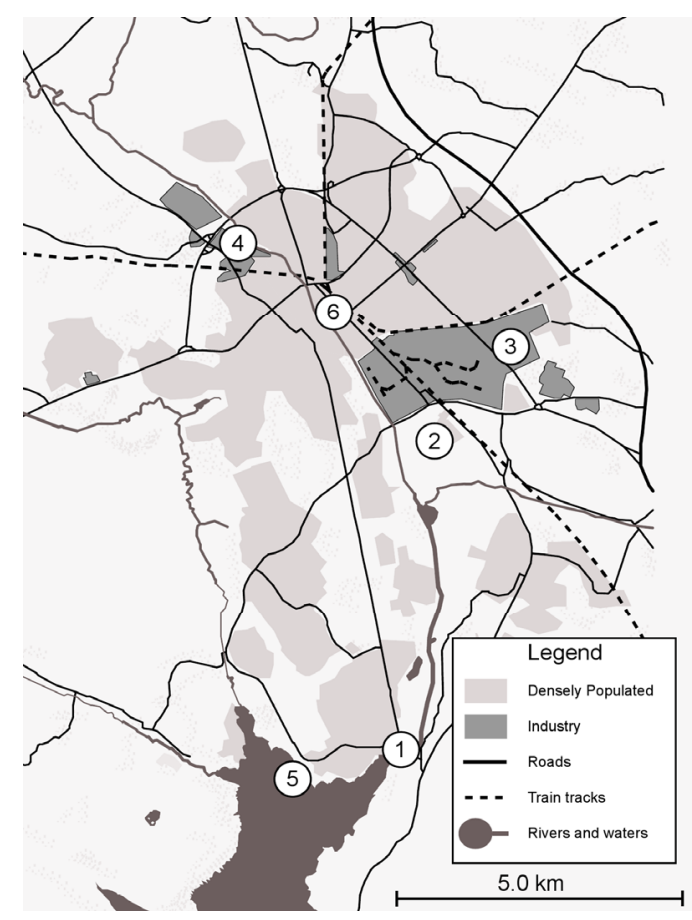

Figure 1: Schematic representation of the city of Uppsala. Numbers denote sampling locations. 1) Flottsund [rural], 2) Kungsängen [rural], 3) Boländerna [Industrial], 4) Librobäck [Industrial], 5 Skarholmen [rural] and 6) Kungsgatan, Drottninggatan and Stora Torget [Central City].

a clean background: a) five locations in rural background, b) two locations of industrial environment, c) three locations in inner city. For all but one (rural) sampling two separate samples were collected: one on ground level and one at least $1.5 \mathrm{~m}$ high. See figure 1 for a more detailed presentation of sampling locations. Sites 1, 2 and 5 in figure 1 were collated into 'Rural Background' group, sites 3 and 4 were collated into 'Industrial Area' group and site 6 into 'Central Uppsala' group.

\subsection{PM collection onto polyamide filters}

Collection of airborne particles was done by placing custom plastic stubs holding Nucleopore polyamide filters (filter $\varnothing 10 \mathrm{~mm}$ with a central portion of $\varnothing 4.0 \mathrm{~mm}$ over a hole in the stub for airflow, pore-size approx. $0.5 \mu \mathrm{m}$, see figure 2 ) onto a plastic mouthpiece $(\varnothing 3.0 \mathrm{~mm})$ on a metallic pipe or hose $(\varnothing 4.0 \mathrm{~mm}, \mathrm{~L} 45 \mathrm{~cm}$ or $4 \mathrm{~m}$ respectively) fixed to an air-suction unit. Stubs and air suction unit were supplied by Sempore AB. The suction unit, when switched on, will continuously 


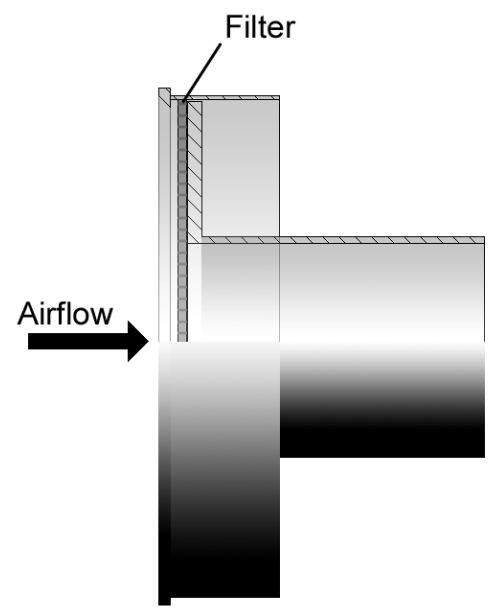

Figure 2: Schematic drawing and cross-section of the custom plastic stub with Nucleopore filter mounted onto the suction device. Arrow is showing airflow during suction.

pump air and aspirate air in front of the leading hose through the filter stub in order to trap any particles onto the polyamide filter. In each case approximately 0.8 liters of air was drawn through the filter taking 30 minutes. The filter stubs were stored pre- and post use in sealed stub-carousels at room temperature.

\subsection{Analysis of filters on TM1000-EDS}

Running settings for the TM1000 and EDS were the same as used for the determination of the elemental detection limit. Sample stubs were placed on a special stub holder which tilted the samples $15^{\circ}$ (for signal gain). The diameter of isolated particles were measured using the built-in measurement tool and then scanned for elemental composition by focusing the electron beam on the particle in Spot-mode for 30-45 seconds, to ascertain that a significant amount of signal counts were detected. Signals were classified for elemental composition using the standard Oxford Instruments Analytical Ltd. Swift-ED software, 341 individual particles were characterized.

\section{Results and discussion}

Particles were collected at two dates and analyzed for elemental content. In total 341 particles, 11-60 per sample, were analyzed and classified based on elemental composition. 281 of these particles were selected for presentation due to conforming to size restrictions (less than $10 \mu$ diameter) and elimination of erroneous results, see table 1 . The Swift-ED software calculated a $\mathrm{wt}^{\mathrm{\%}} \mathrm{o}_{\text {- }}$ 
Table 1: Amount of collected particles and size distribution in sampled areas.

\begin{tabular}{lllll} 
& PM10 & \multicolumn{3}{c}{ PM2.5 } \\
Location & Number & Mean size $(\mu \mathrm{m})$ & Number & Mean size $(\mu \mathrm{m})$ \\
\hline Central Uppsala & 32 & 4.98 & 74 & 1.25 \\
Industrial Area & 23 & 4.34 & 56 & 1.32 \\
Rural Background & 15 & 5.10 & 42 & 1.18 \\
\hline
\end{tabular}

occurrence of all elements automatically or manually selected. These were collated for the type of area the analyzed particles were collected at: Inner City, Industrial area and Rural Background respectively, as shown in figure 3. SD were calculated for each classified sub-group and an averaged SD was calculated from these for the element abundances in each type of collection area. The graphs in fig. 3 could serve as a possible elemental fingerprint of the given areas providing information on elemental occurrence and the size-mode distribution of the elements. As expected the mineral background in all sample areas (alumino/calcium-silicates) and size-modes is dominant, although a slight overrepresentation of approximately $10 \mathrm{wt} \% \mathrm{Si}$ can be seen in the Industrial Area PM10 and also an underrepresentation of $\mathrm{Ca}$ in the same. The City and Industrial Area contain substantially more iron (Fe), especially in the PM2.5 size mode, than the Rural Background. Road traffic and industrial activity is the most plausible explanation for a source as the concentration is highest in the central city and diminishes outside of the city, with diminishing traffic and industrial activity. This observation is also concurrent with a report by Bennet [19] stating

a)

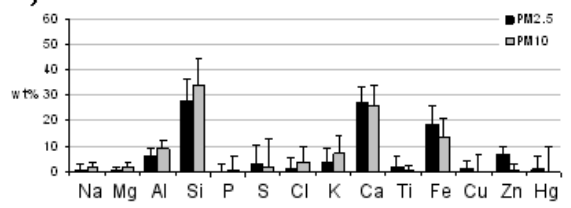

b)

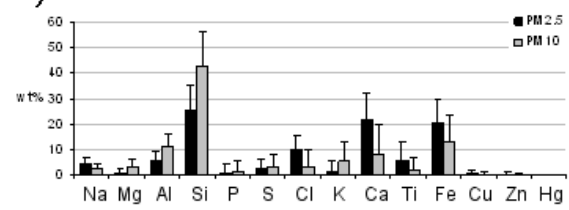

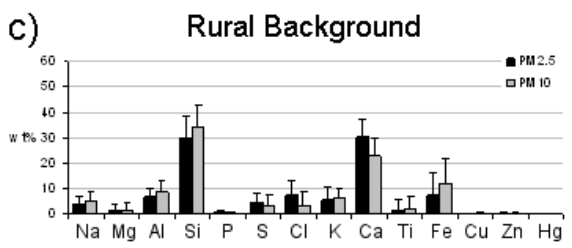

Figure 3: Elemental occurrence averaged in $\mathrm{wt} \%$ for specific areas in the study: a) Inner city Uppsala, b) Industrial area Boländerna and Librobäck and c) Rural Background for Flottsund and Skarholmen. Black bars denote PM2.5 and grey bars denote PM10. Error bars show weighted average SD. 
that Fe-containing PM2.5 particles are mostly derived from vehicle and/or combustive activity. The industrial activity could also pose as a source for the higher occurrence of chlorine $(\mathrm{Cl})$ in the Industrial area compared to the other areas as $\mathrm{Cl}$ is of common use in many industrial processes and is less common in ambient natural mineral. Central City Uppsala also had minute amounts of copper $(\mathrm{Cu})$, zink $(\mathrm{Zn})$ and mercury $(\mathrm{Hg})$ not seen to any appreciable amount in the other areas hailing possibly from colour pigments and the like. The relatively high amount of $\mathrm{Hg}$ is derived from a single particle with almost pure $\mathrm{HgS}$ content (Hg to $\mathrm{S}$ ratio of 1.00). More extensive studies would be needed of a given area to produce more conclusive evidence of excessively represented elements over different size modes of a given area, yet the possibility, using the method used in this study, remains viable, especially if coupled to wind spreading studies and temporal changes.

All collected and analyzed particles were grouped by spectral similarities and ordered into groups of similar elemental composition. The idea is that any particles captured and analyzed can be traced to a database with known particles and reference materials and in that way given a plausible source. For comparison Figure 4 shows an elemental spectrum for a possible asphalt particle (Fig. 4a).
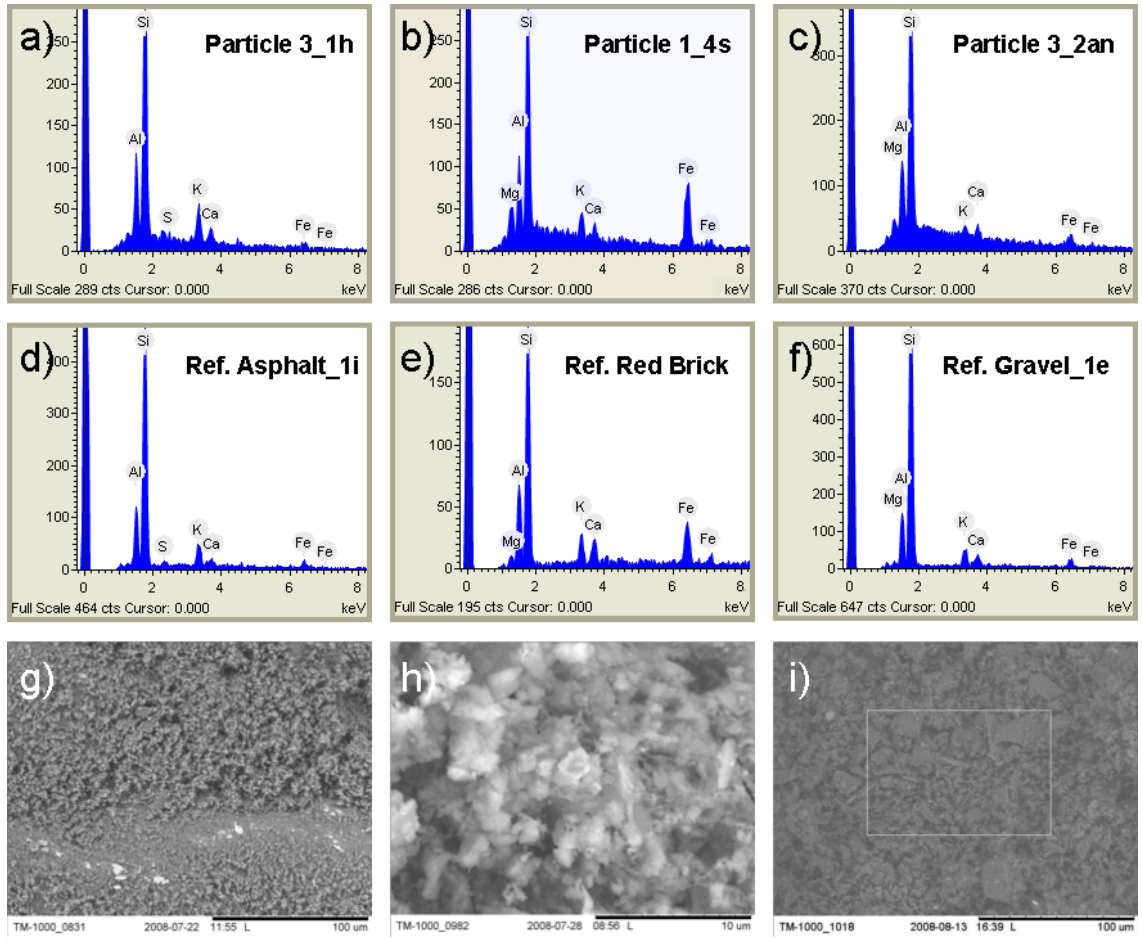

Figure 4: Elemental spectra for particles (a, b and c) and representative reference materials of d) asphalt, e) red brick and f) road gravel with accompanying SEM images of respective reference materials. 
This particle is found to correspond to the area-spectra of a ground sample of asphalt (Fig. 4d). Due to the slight heterogeneous nature of the asphalt sample (a mixture of mainly minerals and some grains of other substances) a spectra

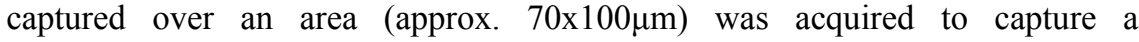
representative spectra of the material. The particle and asphalt reference spectra coincide well with minor differences in trace elements. The same procedure was performed for two other particles showing a possible particle from red brick materials, with some added $\mathrm{Ca}$ from the inhomogeneous background, and from ordinary road gravel (Figs. $4 \mathrm{~b} / 4 \mathrm{e}$ and Figs. 4c/4f respectively). Any identification performed in this way will not yield perfect results due to varying mineral components etc. but will give a good indication of a possible source of the particle. This information together with information on the collection area could serve as a tool for monitoring particle sources.

The main limitation of the standard tabletop SEM-EDS equipment in regards to this study is the inability to detect lighter elements than $\mathrm{Na}$, specifically the carbon, nitrogen and oxygen content. Capturing the carbon and nitrogen content of a sample would give a clear indication whether the material is organic in nature and the oxygen content would show definitely if the studied sample contained oxide compounds. It can be imagined that if it were possible using a tabletop SEM it would confer a major advantage to the type of analysis performed in this study. Other methods of characterizing the organic content [22] and/or the total elemental content e.g. by Kang et al. [27] are available, but require specialist equipment. This can be a hindrance for e.g. local city municipalities wishing to analyze a source of particle emission. With an EDSfitted tabletop SEM this can be easily done by an untrained person, travelling to a location, collecting samples and analyzing them shortly after collection. In extreme cases the tabletop SEMs can be moved close to the source if needed requiring only a standard electrical power supply, i.e. wall plug, for use. These types of equipment represent unprecedented possibilities of microanalysis of inorganic elements. As mentioned before the EDS-detector has an elemental detection cut-off at $0.1-0.5 \mathrm{wt} \%$ so trace elements remain undistinguished from the background noise and other more precise methods are needed for analyzing these. Still these types of equipment present the possibility of quick and easy analysis for inorganic elements at reasonable detection limits of PM10 and PM2.5 particle samples at low instrumentation cost.

\section{Supplementary materials}

Detailed description of the collected particulate matter, including the collection area type, geographic location, chemical composition, morphology/appearance of particles and EDS detection sensitivity is available on request from the authors.

\section{Acknowledgements}

The current study has been endorsed by The Swedish Research Council for Environment, Agricultural Sciences and Spatial Planning (FORMAS). The 
authors would like to thank Anders Gambe of Sempore AB for invaluable insight and help in collecting particles. We would also like to acknowledge Mats Eriksson and Jan Magnusson of Bruker AXS for instrumentation help and data analysis.

\section{References}

[1] Lebowitz, M. D. Epidemiological studies of the respiratory effects of air pollution. Eur. Respir. J., 9, pp. 1029-1054, 1996.

[2] Künzli, N.; Kaiser, R.; Medina, S.; Studnicka, M.; Chanel, O.; Filliger, P.; Herry, M.; Horak Jr., F.; Puybonnieux-Texier, V.; Quénel, P.; Schneider, J.; Seethaler, R.; Vergnaud, J-C.; Sommer, H. Public-health impact of outdoor and traffic-related air pollution: a European assessment. Lancet, 356, pp. 795-801, 2000.

[3] WHO (World Health Organization), Air Quality Guidelines for Particulate Matter, Ozone, Nitrogen Dioxide and Sulphur Dioxide: Global Update 2005, WHO Press Geneva Switzerland, 2006.

[4] Donaldson, K.; Stone, V.; Seaton, A.; MacNee, W. Ambient Particle Inhalation and the Cardiovascular System: Potential Mechanisms. Environ. Health Persp., 109(S4), pp. 524-527, 2001.

[5] Sioutas, C.; Delfino, R. J.; Singh, M. Review: Exposure Assessment for Atmospheric Ultrafine Particles (UFPs) and Implications in Epidemiologic Research. Environ. Health Persp., 113(8), pp. 947-955, 2005.

[6] Delfino, R. J.; Sioutas, C.; Shaista, M. Review: Potential Role of Ultrafine Particles in Associations between Airborne Particle Mass and Cardiovascular Health. Environ. Health Persp, 113 (8), pp. 934-946, 2005.

[7] Nemmar, A.; Hoet, P. H. M.; Vanquickenborne, B.; Dinsdale, D.; Thomeer, M.; Hoylaerts, M. F.; Vanbilloen, H.; Mortelmans, L.; Nemery, B. Passage of Inhaled Particles Into the Blood Circulation in Humans. Circulation, 105, pp. 411-414, 2002.

[8] WHO (World Health Organization), Air Quality Guidelines for Europe: second edition, WHO Regional Publications, European Series: No. 91, 2000.

[9] Pope III, C. A.; Ezzati, M.; Dockery, D. W. Fine-Particulate Air Pollution and Life Expectancy in the United States. N. Engl. J. Med., 360, pp. 376386, 2009.

[10] Brunekreef, B.; Holgate, S. T. Review: Air Pollution and Health. Lancet, 360, pp. 1233-1242, 2002.

[11] Bernstein, J. A.; Alexis, N.; Barnes, C.; Bernstein, I. L.; Nel, A.; Peden, D.; Diaz-Sanchez, D.; Tarlo, S. M.; Williams, B. Health effects of air pollution. J. Allergy Clin. Immunol. 114(5), pp. 1116-1123, 2004.

[12] Soto, K. F.; Garza, K. M.; Shi, Y.; Murr, L. E. Direct contact cytotoxicity assays for filter-collected, carbonaceous (soot) nanoparticulate material and observations of lung cell response. Atmos. Environ., 42, pp. 1970-1982, 2008. 
[13] De Viscaya-Ruiz, A.; Gutiérrez-Castillo, M. E.; Uribe-Ramirez, M.; Cebrián, M. E.; Mugica-Alvarez, V.; Sepúlveda, J.; Rosas, I.; Salinas, E.; Garcia-Cuéllar, C.; Martínez, F.; Alfaro-Moreno, E.; Torres-Flores, V.; Osornio-Vargas, A. H.; Sioutas, C.; Fine, P. M.; Singh, M.; Geller, M. D.; Kuhn, T.; Miguel, A. H.; Eiguren-Fernandez, A.; Schiestl, R. H.; Reliene, R.; Froines, J. Characterization and in vitro biological effects of concentrated particulate matter from Mexico City. Atmos. Environ., 40, pp. S583-592, 2006.

[14] Karlsson, H. L.; Gustaffson, J.; Cronholm, P.; Möller, L. Size-dependent toxicity of metal oxide particles - a comparison between nano- and micrometer size. Toxicology Letters, 188, pp. 112-118, 2009.

[15] Morata, D.; Polvé, M.; Valdés, A.; Belmar, M.; Dinator, M. I.; Silva, M.; Leiva, M. A.; Aigouy, T.; Morales, J. R. Characterisation of aerosol from Santiago, Chile: an integrated PIXE-SEM-EDX study. Environ. Geol., 56, pp. 81-95, 2008.

[16] Viksna, A.; Selin-Lindgren, E.; Standzenieks, P.; Jacobsson, J. EDXRF and TXRF analysis of elemental size distributions and environmental mobility of airborne particles in the city of Riga, Latvia. X-Ray Spectrom., 33, pp. 414-420, 2004.

[17] Perrino, C.; Canepari, E.; Cardarelli, E.; Catrambone, M.; Sargolini, T. Inorganic constituents of urban air pollution in the Lazio region (Central Italy). Environ. Monit. Assess., 136, pp. 69-86, 2008.

[18] Godoi, R. H. M.; Braga, D. M.; Makarovska, Y.; Alfoldy, B.; CarvalhoFilho. M. A.S.; Van Grieken, R.; Godoi, A. F. L. Inhalable particulate matter from lime industries: Chemical composition and deposition in human respiratory tract. Atmos. Environ., 42, pp. 7072-7033, 2008.

[19] Bennet, C.; Jonsson, P.; Selin-Lindgren, E. Concentration and sources of trace elements in particulate air pollution, Dar es Salaam, Tanzania, studied by EDXRF. X-Ray Spectrom., 34, pp. 1-6, 2005.

[20] Miranda, R.; Tomaz, E. Source Characterization of urban aerosol in Campinas, São Paulo, Brazil. Atmos. Research, 87, pp. 147-157, 2008.

[21] Pérez, N.; Pey, J.; Querol, X.; Alastuey, A.; López. J. M.; Viana, M. Partitioning of major and trace components in $\mathrm{PM}_{10}-\mathrm{PM}_{2.5}-\mathrm{PM}_{1}$ at an urban site in Southern Europe. Atmos. Environ., 42, pp. 1677-1691, 2008.

[22] Kleeman, M. J.; Riddle, S. G.; Robert, M. A.; Jakober, C. A.; Fine, P. M.; Hays, M. D.; Schauer, J. J.; Hannigan, M. P. Source Apportionment of Fine (PM) and Ultrafine (PM) Airborne Particulate Matter during a Severe Winter Pollution Episode. Environ. Sci. Technol., 43, pp. 272-279, 2009.

[23] Prather, K. A.; Nordmeyer, T.; Salt, K. Real-Time Characterization of Individual Aerosol Particles Using Time-of-Flight Mass Spectrometry. Anal. Chem., 66, pp. 1403-1407, 1994.

[24] Sodeman, D. A.; Toner, S. M.; Prather, K. A. Determination of Single Particle Mass Spectral Signatures from Light-Duty Vehicle Emissions. Environ. Sci. Technol., 39, pp. 4569-4580, 2005.

[25] Hitachi High-Technologies Corp., Product Description TM-1000 HTDE136 2007.8 Tokyo Japan, 2007. 
[26] LVF (Stockholms och Uppsala Läns Luftvårdsförbund), Luftkvalitet $i$ Stockholms och Uppsala län samt Gävle och Sandviken kommun: Kontroll och jämförelser med miljökvalitetsnormer år 2007, SLB-analys Stockholm Sweden, 2008.

[27] Kang, S.; Hwang, H. J.; Park, Y. M.; Kim, H. K.; Ro, C-U. Chemical Compositions of Subway Particles in Seoul, Korea Determined by a Quantitative Single Particle Analysis. Environ. Sci. Technol., 42, pp. 90519057, 2008. 